\title{
Open questions on the nature of Parkinson's disease: from triggers to spreading pathology
}

\author{
Lei Mou, ${ }^{1}$ Wei Ding, ${ }^{1}$ Pedro Fernandez-Funez ${ }^{2}{ }^{2}$
}

${ }^{1}$ Neurology, Rizhao Hospital of Traditional Chinese Medicine, Rizhao, China

${ }^{2}$ Biomedical Sciences, University of Minnesota Medical School

- Duluth Campus, Duluth,

Minnesota, USA

\section{Correspondence to}

Dr Pedro Fernandez-Funez, Biomedical Sciences, University of Minnesota Medical School - Duluth Campus, Duluth, MN 55812, USA;

pfernand@d.umn.edu

Received 7 April 2019

Revised 16 June 2019

Accepted 23 June 2019

Published Online First 4

September 2019

Check for updates

(c) Author(s) (or their employer(s)) 2020. No commercial re-use. See rights and permissions. Published by BMJ.

To cite: Mou L, Ding W, Fernandez-Funez $P$.

J Med Genet 2020:57:73-81.

\section{ABSTRACT}

Parkinson's disease (PD) is a movement disorder identified more than 200 years ago; today it is defined by specific motor symptoms that together receive the name of parkinsonism. PD diagnosis is reached with the full parkinsonian syndrome, but in recent years, a series of non-motor symptoms have arisen as intrinsic components of PD. These non-motor symptoms are variable, creating a widely heterogenous disease presentation. Some non-motor symptoms appear in late disease stages and are explained as the natural progression of PD pathology into other brain centres, including the frontal cortex. Other symptoms can appear a decade or earlier preceding PD diagnosis, particularly hyposmia (loss of smell) and constipation. These early symptoms and the accompanying protein pathology have stimulated a lively conversation about the origin and nature of PD and other related conditions: some authors propose that PD starts in the olfactory mucosa and the gut due to direct exposure to toxins or pathogens. This pathology then travels by anatomically interconnected networks to the midbrain to cause motor symptoms and the cortex to cause late complications. Other models propose that PD develops in multiple independent foci that do not require pathology spread. We will review these hypotheses in the context of recent developments regarding the spread of amyloids and propose a mixed model where a multifocal origin explains the variable presentation of $P D$, while cell-to-cell spread explains stereotypical disease progression.

\section{INTRODUCTION}

Parkinson's disease (PD) is the second most common neurodegenerative disease affecting the elderly and the most prevalent movement disorder. ${ }^{1}$ PD is characterised mainly by a combination of motor symptoms described more than 200 years ago $^{2}$ known as parkinsonism or parkinsonian syndrome: resting tremor, bradykinesia, rigidity and abnormal gait. Although variable and not diagnostic on their own, patients with PD also present an array of non-motor symptoms that indicate a widespread pathology of the central and peripheral nervous systems (CNS, PNS). Cognitive dysfunction, psychiatric disturbances, incontinence and autonomic disorders are some of the symptoms that develop late in the disease, typically following the diagnosis of PD. Remarkably, hyposmia, gastrointestinal (GI) problems, sleep disturbances and depression usually appear before PD diagnosis, sometimes by a decade. Hyposmia and constipation have been suggested to be the first signs of a PD pathology that spreads from the periphery to the CNS. ${ }^{34}$ Multiple PD hypotheses fail to completely explain the complexity and heterogeneity of PD. We will review here the current state of the field, the relevance of the early non-motor symptoms and propose a unifying hypothesis that explains the heterogeneity of PD and related disorders.

\section{Motor features of PD: parkinsonism and dopamine loss}

The motor deficits in PD are relatively wellunderstood today. Parkinsonism is caused by understimulation of dopamine receptors in the striatum. The basal ganglia are complex brain nuclei with excitatory and inhibitory relays involved in many important processes, including the control of voluntary movement. The origin of parkinsonism is decreased dopamine release in the striatum from dopaminergic neurons whose cell bodies originate in the substantia nigra pars compacta $(\mathrm{SNc})$ in the midbrain. These neurons are progressively lost in patients with PD as indicated by the loss of the dark pigmentation associated with neuromelanin production in the midbrain. The neurofunctional basis of the motor symptoms in PD conform the basis for the current symptomatic treatments. Supplementation of patients with PD with levo-dopamine (L-dopa) restores most of the motor symptoms, supporting the key modulatory roles of dopamine in striatal neurons. Additionally, electrical stimulation of the subthalamic nuclei downstream of the abnormal basal ganglia through deep brain stimulation partially restores motor symptoms and allows decreasing the dose of L-dopa along with its side effects (dyskinesia). Unfortunately, these symptomatic treatments are only temporary as the pathology progressively spreads to other brain centres causing new debilitating symptoms.

The main pathological finding in PD is the presence of Lewy bodies (LB) in the neurons responsible for the PD symptoms. LB are composed of cytoplasmic aggregates that accumulate in the cell body (LB) and neurites (Lewy neurites) containing mainly misfolded and aggregated $\alpha$-synuclein ( $\alpha$-syn) protein. $\alpha$-syn plays a key role in PD because of the widespread distribution of LB pathology, its connection to familial forms of PD and studies using $\alpha$-syn to stage PD progression. ${ }^{4-6}$

Non-motor symptoms in PD: more than dopamine In addition to the cardinal motor symptoms, PD has several distinguishing non-motor features that makes it particularly challenging from both clinical 
and basic science perspectives. These symptoms are usually referred to as 'premotor', but that term may be misleading because mild motor symptoms (eg, resting tremor, bradykinesia) may develop years before full PD diagnosis. In this review, we will refer to these symptoms as 'non-motor' and use 'prediagnostic' for those symptoms that appear before full PD diagnosis.

Among the non-motor symptoms in PD, incontinence, dementia, hallucinations, depression and other psychiatric disturbances, dysphagia (difficulty swallowing), hypophonia (weak voice), orthostatic hypotension, cardiac autonomic dysfunction and sexual disfunction tend to appear after PD diagnosis. More interesting are the symptoms that may appear in the prediagnostic phase of PD: hyposmia, constipation, sleep alterations and depression. Patients with PD can present with some of these early symptoms or none, making the clinical presentation highly heterogeneous. Of these early symptoms, hyposmia and constipation have prevalence around $90 \%$ depending on the study and, more importantly, implicate peripheral tissues exposed to potential exogenous PD triggers.

These early peripheral PD symptoms bring up interesting questions about the nature and origin or PD: Does PD originate first in peripheral tissues? Does PD start peripherally and spreads to the midbrain and cortex or does it start in multiple foci simultaneously? Is PD one heterogeneous disease-a syndrome-or the convergence of multiple independent pathologies? Is PD an infectious disease, a systemic disease, a multifocal disease or a brain disease with concurrent old-age symptoms? What are the contributions of genetics and environmental exposures to PD? We will review the current knowledge on the early peripheral non-motor symptoms linked to PD and discuss the best models that explain the nature of PD.

\section{Hyposmia/anosmia}

Hyposmia is one of the many changes associated with normal ageing, with $25 \%$ of the general population showing loss of smell (reviewed in Refs. 7-9). However, hyposmia appears at a younger age and is more prevalent in patients with PD compared with the general population. Although it varies in the literature, recent data using standardised and sensitive smell testing suggest that up to $90 \%$ of patients with PD display some degree of hyposmia or complete anosmia. ${ }^{710}$ Studies in ageing populations or relatives of patients with PD found that those individuals with hyposmia had increased odds of developing PD 4 and 5 years later, respectively. ${ }^{11}{ }^{12}$ Moreover, patients diagnosed with hyposmia had 11-fold higher odds of developing incidental LB pathology without $\mathrm{PD}$, further supporting the close connection between these pathologies. ${ }^{13-15}$

Patients with PD are not characterised by a specific smell loss; thus, no particular type of olfactory neuron demonstrates increased vulnerability. ${ }^{16}{ }^{17}$ Despite the robust loss of smell, pathological studies describe a mostly normal olfactory epithelium. ${ }^{18}$ A detailed analysis of the olfactory epithelium in autopsied tissue (necropsies) found no $\alpha$-syn pathology in olfactory neurons. ${ }^{19}$ However, a more recent study detected LB pathology in six out of eight patients with PD. ${ }^{20}$ Biopsies of the olfactory epithelium (early disease stages) found that antibodies against specific olfactory neurons showed the same distribution in patients with PD, non-PD hyposmic controls and normal controls $^{20}$ and no LB pathology ${ }^{18}$ suggesting that this tissue is not particularly vulnerable in PD. In contrast, mitral cells, which receive direct input from epithelial neurons, the olfactory tracts (olfactory nerve) and several closely connected brain regions involved in olfaction (amygdala, entorhinal cortex, the piriform cortex and olfactory tubercle) all show prominent LB pathology. These observations highlight the differential vulnerability to LB pathology in the olfactory system and locates the dysfunction to the olfactory tracts and olfactory centres of the brain. Although the volume of the olfactory bulb appears to be normal by anatomical MRI, with variations depending on the study, ${ }^{21}$ more specific imaging modalities have detected specific changes. ${ }^{22-27}$ Smell loss does not respond to L-dopa treatment, indicating nonspecific neurotransmitter changes (dopamine, serotonin, acetylcholine, norepinephrine) associated with hyposmia. ${ }^{782829}$ These findings have two main implications: (1) hyposmia could be used to identify patients in prodromal PD and (2) as one of the first pathogenic events in PD, hyposmia could help identify the triggering agent(s) as well as the mechanism(s) mediating the spread of pathology to the midbrain and cortex.

Hyposmia has low specificity for predicting PD since many conditions can result in loss of smell. A smell study following patients for 5 years only showed 53\% accuracy predicting future PD diagnosis. ${ }^{30}$ However, combining hyposmia with other early non-motor PD symptoms (see below) or with imaging abnormalities shows significantly higher predictive value for PD. ${ }^{31} 32$ On the other hand, hyposmia is a poor marker for PD progression, possibly because the pathology in the olfactory areas of the brain starts early and progresses faster than the motor, cognitive and psychiatric symptoms. A potential clue to the olfactory pathology in PD comes from its correlation with other PD symptoms. Hyposmia is not associated with either the tremordominant or akinetic-dominant types of PD..$^{33}$ However, hyposmia associates with cognitive and psychiatric disturbances, including apathy, anxiety and depression, indicating a common central susceptibility for these symptoms. ${ }^{35} 36$ Whereas overall cognitive performance seems normal among patients with PD with hyposmia, specific aspects of cognitive decline like verbal memory, executive function and attention, seem impaired in $\mathrm{PD}^{37}$ These associations can increase the specificity and accuracy of early PD diagnosis and contribute to elucidate the origin and nature of the pathology.

\section{Constipation}

GI alterations are another common non-motor feature of PD. The prevalence and severity of GI problems increase with the progression of $\mathrm{PD}$, making these problems part of the natural history of PD. ${ }^{38} 39$ General GI complications may be underreported with $30 \%-90 \%$ of patients with PD complaining of different GI problems. ${ }^{40}{ }^{41}$ In addition to affecting the quality of life and causing social stigma, alterations in GI function can interfere with the absorption of medications in the large intestine, exacerbating motor fluctuations in patients with PD. Among the many GI complications, the most common is constipation, with a prevalence that has been reported between $30 \%$ and $80 \%$, sixfold more common in PD than in age matched controls. More importantly for this review, constipation is one of the earliest symptoms associated with PD, with a presentation up to 15 years before PD diagnosis. ${ }^{42-45}$ In fact, individuals with fewer bowel movements are at a higher risk of developing PD 5 years later. ${ }^{43}$ However, the sensitivity of constipation alone for predicting PD is low.

The enteric nervous system (ENS) is a semiautonomous neuronal network that regulates the function of different sections of the gut. Neurons of the ENS produce dopamine and other neurotransmitters that are locally released to control intestinal function. The ENS contains several types of neurons grouped in two plexi, the deeper Meissner's plexus in the submucosa, 
which produces dopamine, and the more superficial myenteric Auerbach's plexus. These intrinsic GI neurons communicate profusely with each other, while the Auerbach plexus synapse with sensory, sympathetic and parasympathetic fibres travelling through the vagus nerve. The cell bodies of these vagal neurons are located in the brainstem, which lay in close proximity to $\mathrm{SNc}$ neurons in the midbrain, providing an anatomical link between GI and motor symptoms. Most patients with PD show LB pathology in ENS neurons and vagus nuclei, which express high levels of $\alpha$-syn. Additionally, LB are commonly found in the GI in non-PD individuals, which could identify a population with prodromal PD, other synucleinopathies, or incidental pathology due to ageing. ${ }^{46} 47$ Despite this prevalent LB pathology, no cell loss is detected in the Auerbach plexus. ${ }^{48}$ On the other hand, the Meissner's plexus suffers around $15 \%$ cell loss plus significant decrease in dopamine release, which could be sufficient to explain the constipation. ${ }^{49}$ This $15 \%$ cell loss is in sharp contrast to that in the $\mathrm{SNc}$, where over $80 \%$ dopaminergic cell loss is detected by the time the motor symptoms are diagnosed. A relatively small cell loss in the ENS seems to be enough to cause constipation and other GI symptoms, uncovering a highly susceptible network to PD pathology. These symptoms are not reversed by the typical L-dopa/carbidopa cocktail because carbidopa prevents the conversion of L-dopa into dopamine in the periphery. However, local GI treatment with L-dopa or other dopamine agonist as well as other neurotransmitters can alleviate these symptoms.

\section{The spreading pathology of PD}

The early LB pathology of ENS neurons has been interpreted as suggesting that the PD pathology starts in the gut via exogenous agents: the 'dual-hit hypothesis'. ${ }^{4}$ This seminal work mapped the distribution of LB pathology to stage PD progression from I to VI. The study concluded that the PD pathology actually starts in the olfactory epithelium and the gut as a consequence to exposure to toxins or neurotropic pathogens that infect neurons or start an inflammatory cascade that damages peripheral neurons, spreads to postsynaptic brainstem neurons followed by basal ganglia and frontal cortex by anterograde transmission (rostral spread). ${ }^{3}$ These observations have two important implications: (i) exogenous triggers of $\alpha$-syn pathology attack peripheral tissues first and (ii) $\alpha$-syn aggregates actively spread from the PNS to and throughout the brain. We will review these concepts in the following chapters.

\section{Genetics versus environment}

What is the evidence supporting the idea that exogenous agents are responsible for initiating the peripheral PD pathology? Idiopathic PD accounts for $\sim 90 \%$ of all the cases, although this number includes a significant number of carriers of PD mutations with no family history. ${ }^{50-52}$ At this time, no infectious agent has been associated with PD. It is well known that PD has higher incidence in rural/farm areas and this may be related to the exposure to pesticides and well water drinking containing high levels of heavy metals. ${ }^{51}$ In this sense, the GI can be viewed as the gateway connecting the environment to the brain. Animal models confirm that ingestion of certain pesticides (rotenone, paraquat) or 1-methyl-4-phenyl-1,2,3,6-tetrahydropyridine (MPTP) can initiate a PD-like pathology. MPTP disrupts the respiratory chain and causes oxidative stress, which has been proposed as an upstream regulator of $\alpha$-syn aggregation. In fact, rodent models exposed to low concentrations of rotenone in the gut show $\alpha$-syn aggregation in and dysfunction of the ENS, ${ }^{53-55}$ followed by LB pathology in the vagus nerve. Longer rotenone exposure leads to motor signs and decreased dopamine in the striatum, suggesting a link to the motor pathology. ${ }^{56}$ Interestingly, this spread of LB pathology is partially interrupted by excision of the vagus nerve (vagotomy), which confirms the potential of the peripheral pathology to spread into the central brain by GI-vagal innervation. ${ }^{56}{ }^{57}$ Mice treated with pesticides (rotenone, paraquat), MPTP or 6-hydroxidopamine develop symptoms consistent with $\mathrm{PD}$, including LB pathology, providing further mechanistic links to PD pathogenesis. However, only a small fraction of patients with PD is exposed to these agents while not all rural populations develop PD. Thus, these agents impact the PD burden by increasing the likelihood of developing $\mathrm{PD}$ in combination with other factors, mainly genetics, ageing and lifestyle (figure 1).

Similar to Alzheimer's disease (AD), most PD is sporadic, but around $10 \%$ of PD cases are purely familial, where the patient has a first-degree relative diagnosed with PD. As opposed to $\mathrm{AD}, \mathrm{PD}$ genetics is highly complex, with a variety of autosomal-dominant, autosomal-recessive and incomplete penetrance loci that do not fit in a linear pathway. ${ }^{58}$ The main genetic clue to PD came from the identification of mutations in $\alpha$-syn in a small number of autosomal-dominant familial forms of PD. The fact that point mutations in $\alpha$-syn as well as duplications and triplications of wild type $\alpha$-syn cause highly penetrant autosomal-dominant PD connects mechanistically $\alpha$-syn intrinsic propensity to misfold to the initiation of LB pathology and PD (figure 1). $\alpha$-syn is a small, mostly disordered protein abundant in synaptic terminals and the nucleus. Moreover, oxidative stress has been shown to accelerate $\alpha$-syn aggregation: MPTP and some pesticides interfere with the respiratory chain in the mitochondria, which deplete energy reserves and cause oxidative stress and $\alpha$-syn aggregation (reviewed in ${ }^{59}$ ) (figure 1).

Despite the central role of $\alpha$-syn in PD, the most common familial form of PD is linked to mutations in LRRK2 (leucinerich repeat kinase 2), a kinase of mostly unknown function. Missense mutations (eg, G2019S) increase LRRK2 kinase activity, disrupting several targets implicated in vesicular trafficking and proteostasis. ${ }^{60}$ Eight different mutations in LRRK2 have been identified in familial PD, most of them demonstrate low penetrance, but they typically associate with LB pathology. Additionally, mutations in seven additional genes cause autosomal-dominant (VPS13) or autosomal-recessive PD (parkin, PINK1) in a small number of families (low frequency, high impact) (reviewed in $^{558}$ ) (figure 1). Moreover, PD shows a strong heritability (pattern of familial clustering, over 30\%) that is well above the known $10 \%$ strictly familial inheritance. ${ }^{52}$ Part of this discrepancy is due to PD loci with incomplete penetrance (LRRK2, Glucocerebrosidase), inaccuracies in the medical records and individuals with prodromal PD that die of other causes. New PD genes are discovered each year, including high frequency-low impact genes that may have cumulative effects through combinations of variants. Overall, growing evidence indicates a stronger than expected genetic component in PD (figure 1). Genetic perturbations affecting mitochondrial metabolism, vesicular trafficking and protein clearance are more likely causes of PD than exogenous agents like pathogens or toxins. Unfortunately, the most relevant PD genes are not functionally linked in a linear pathway, leaving significant gaps in the understanding of the pathogenic mechanisms of familial PD and, by extension, all forms of PD. 

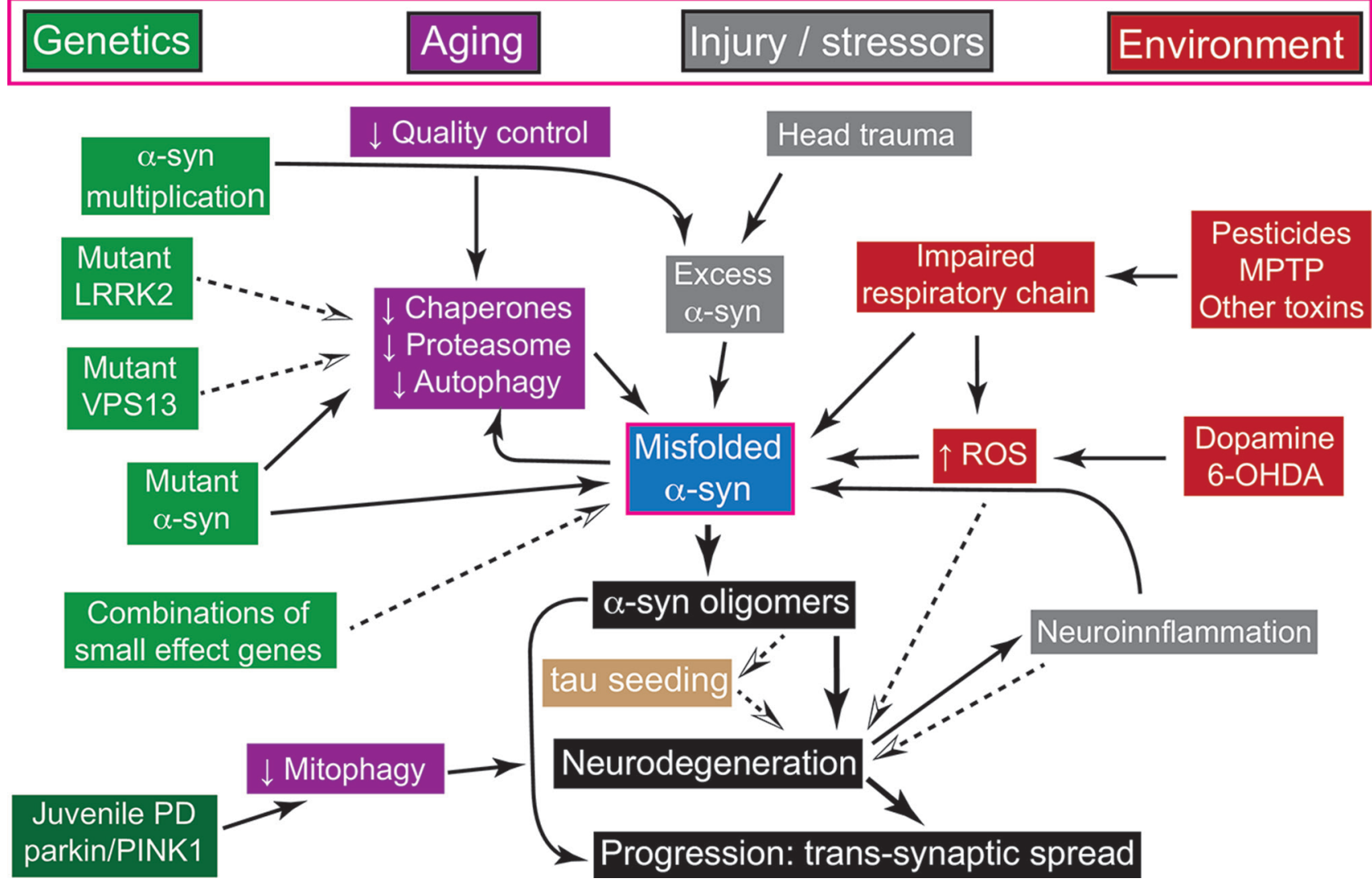

Figure 1 A hypothesis integrating multiple triggering factors into a converging pathogenic mechanism. Multiple factors are proposed to interact in the initiation of PD pathology: genetic risks (green boxes), ageing (purple), brain injury/stressors (grey) and environmental exposures (red). Since PD is a late onset disorder, the decline in quality control mechanisms plays a central role in disease. These mechanisms include the activity of chaperones that maintain proteins in their native conformation and the proteasome and autophagy, which degrade protein aggregates and abnormal organelles (eg, mitochondria). Once these protective mechanisms become less effective later in life, WT $\alpha$-syn can misfold and aggregate spontaneously. $\alpha$-syn mutations or extra copies accelerate this propensity of $\alpha$-syn to aggregate. Mutations in other PD genes (LRRK2, VPS31) can disable quality control mechanisms, thus contributing to $\alpha$-syn aggregation. $\alpha$-syn expression is sensitive to stressors like head trauma, thus feeding into the $\alpha$-syn pathway. On the right side, several environmental factors have a direct impact on PD, with some experts proposing $\alpha$-syn-independent mechanisms of toxicity (dashed arrow from ROS). However, MPTP and rotenone cause $\alpha$-syn aggregation in animal models, suggesting a converging $\alpha$-syn pathology. Neuroinflammation is present in degenerating brains and the presence of reactive astrocytes and microglia can definitely contribute to further neuronal damage. But neuroinflammation likely starts because of neuronal damage and cell loss, thus placing this pathway downstream of other triggers. Finally, we propose that $\alpha$-syn oligomers are the primary triggers of neuronal degeneration and also participate in the stereotypic disease progression by trans-synaptic spread. Recent experimental observations suggest that $\alpha$-syn cross-seeds tau, providing an additional mechanism to explain neurotoxicity and neuronal loss. Intriguingly, some pathogenic pathways are not easily integrated in this model. Mutations in genes causative of juvenile onset PD (dark green) disrupt degradation of abnormal mitochondria, leading to an $\alpha$-syn-independent pathology. These cases support arguments for multiple independent mechanisms triggering PD. An alternative interpretation is that this is a form of parkinsonism that does not fit with the classic symptomatic presentation of PD (eg, juvenile onset, prominent early dystonia) that does not challenge the $\alpha$-syn-centric pathology. Dashed lines indicate suspected mechanisms. This mechanism is an oversimplification of the vast information in the PD field. Many other factors or mechanisms have been proposed to contribute to PD, but we focused on a few prominent factors for clarity. $\alpha$-syn, $\alpha$-synuclein; LRRK2, leucine-rich repeat kinase 2; MPTP, 1-methyl-4-phenyl-1,2,3,6-tetrahydropyridine; 6-OHDA, 6-hydroxidopamine; PD, Parkinson's disease; ROS, reactive oxygen species.

\section{The nature of PD: a multifactorial late onset neurodegenerative syndrome}

The evidence presented so far describes PD as an extraordinarily complex and heterogeneous neurodegenerative disease. In contrast to $\mathrm{AD}, \mathrm{PD}$ pathology directly affects multiple organs, including central, peripheral and autonomic nervous systems, GI, and heart, exhibits highly complex genetics and environmental exposures seem to play a significant role in disease aetiology. These factors combine into a widely heterogeneous disease regarding onset, symptoms and progression rate. The heterogeneity of PD results in a somewhat confusing picture of a disease with no clear logic regarding disease nature, site of origin, aetiology, triggers, progression and so on. The interplay between all the above factors suggests that PD is a multifactorial neurodegenerative process caused by the interaction between normal ageing, neuronal susceptibility, genetic risks and environment exposures. Some of the factors contributing to PD pathology discussed in the literature include aberrant mitochondria activity/oxidative stress, neuroinflammation and synaptic dysfunction ${ }^{50}$ (figure 1). Autopsied PD brains show clear evidence for these alterations, but it is unclear whether they are pathogenic triggers or how much they contribute to pathogenesis. ${ }^{50}$ Despite the abundance of factors purportedly causing or contributing to PD, it is critical to keep in mind that PD is characterised by two prominent and consistent features: late onset (age-related) and the presence of LB pathology. The late onset informs about the key role 
of the decline in physiological activities, specifically problems maintaining quality control mechanisms that prevent disease manifestations earlier in life. The LB pathology is the definitive diagnostic criteria for PD on autopsy, indicating a prominent role for $\alpha$-syn in the pathogenic mechanism, even when other mutant genes may be the triggering factor. Putting this evidence together, it seems likely that ageing, genetics, exposures, lifestyle and other factors converge to alter the proper handling of $\alpha$-syn, a protein prone to misfold and induce toxicity (figure 1).

The heterogeneous symptoms have invited efforts to stratify PD clinically, but these efforts have provided no new insight into disease aetiology or nature. Given this extraordinary variability, it may be more useful to view PD as a syndrome with a continuum of motor and non-motor symptoms reflecting individual susceptibilities at the molecular, cellular, circuit and system levels. ${ }^{58}{ }^{61}$ In fact, several related diseases share symptoms, genetics and pathology with pure PD to consider a wider umbrella for the parkinsonian conditions. ${ }^{5862} \mathrm{~A}$ handful of diseases share both parkinsonism and proteinopathy, including Lewy body dementia (LBD), multiple systems atrophy (MSA), corticobasal degeneration (CBD) and progressive supranuclear palsy (PSP). LBD and MSA are synucleinopathies presenting with parkinsonism and other distinguishing symptoms. CBD and PSP are tauopathies with significant symptomatic overlap with $\mathrm{PD}$, whereas the late stages of $\mathrm{AD}$ and some forms of frontotemporal dementia (FTD)/amyotrophic lateral sclerosis may also develop parkinsonism. These converging features of different proteinopathies suggest that they share relevant pathogenic mechanisms, including progressive spread of pathology through connected networks. These parkinsonian disorders are distinguished by atypical symptoms (abnormal gaze in PSP), symptoms that present too early or progress too fast for PD (dysautonomia in MSA; dementia in LBD, CBD), or proteinopathy (tau in PSP, $\mathrm{CBD}, \mathrm{AD}$ and FTD). The symptomatic and pathological overlap between parkinsonian disorders leads to 'mixed' clinical diagnoses that may or may not be resolved at autopsy. The same can be applied to the genetics, where mutations in $\alpha$-syn, LRRK2 and tau underlie inherited forms of different disorders (or are they varieties of the same disorder?). Traditional disease classifications are useful because disorders that primarily attack the basal ganglia do not respond to L-dopa treatment. But understanding the pathophysiology of parkinsonian disorders may require breaking those traditional definitions to integrate several proteinopathies into a larger entity that explains the complexity and heterogeneity of PD.

Overall, the heterogeneity of the parkinsonian disorders can be brought together under a unifying model. ${ }^{1}$ A primary parkinsonian syndrome is caused by dysfunction of the basal ganglia, either directly (CBD, PSP, MSA, LBD) or due to lack of dopaminergic input (PD). ${ }^{2}$ Early non-motor symptoms appear variably due to independent development of proteinopathy in different foci: SNc, frontal cortex, olfactory cortex, ENS, vagus, olfactory tracts and so on. ${ }^{3}$ Last, late symptoms converge in many conditions as a consequence of cell-to-cell pathology spread through interconnected networks.

\section{The origin of PD: a disease with multifocal origins}

The robust, penetrant non-motor early symptoms in PD indicate a disease with multiple foci. ${ }^{63}$ The key question is whether PD develops simultaneously in independent foci or starts in a single focus that progressively spreads to all the affected tissues. This later idea of a single focus gained support based on the pathology reports from Braak and colleagues. ${ }^{3464}$ The identification of hyposmia and constipation as early and penetrant symptoms in sporadic PD led to the hypothesis that these were the sites of initiation of $\mathrm{PD}$, mediated by the exposure of the olfactory epithelium and the GI to exogenous agents. One conceptual problem with this hypothesis is that the presence of LB does not inform about the origin and progression of the disease since neurons may express different levels of $\alpha$-syn and show different susceptibility to accumulate and survive with LB. Recent studies in several proteinopathies argue for a higher toxicity of soluble aggregates (oligomers) compared with insoluble fibres. ${ }^{6566}$ Oligomers form $\alpha$-syn and other amyloids have been detected in human patients using protein purification techniques ${ }^{6768}$ and conformational antibodies. ${ }^{69}$ Thus, LB accumulation may indicate efficient packaging of $\alpha$-syn in the protective aggresome that could in fact be protective. ${ }^{70}$ Additionally, recent data may contradict the main aspects of the Braak staging system. For instance, about half of the autopsies contradict in some detail the Braak staging, ${ }^{71-74}$ including the observation that 7\%-8\% patients with PD have no vagal LB pathology despite strong SNc pathology, breaking the caudo-rostral link. Moreover, prominent LB can be found in the dorsal vagus nucleus next to degenerated SNc lacking LB, supporting the differential vulnerability of these nuclei. ${ }^{75}$ Other valid criticism includes the observation that in mice LB pathology can spread from the vagus nerve to the $\mathrm{SN}$ pars reticulata, but not to the $\mathrm{SNc}$, which agrees with the lack of direct synaptic connexions ${ }^{76}$ Moreover, patients or mice subjected to vagotomies still develop PD, although at slightly lower rates. ${ }^{57} 77$ These are relatively small differences, but preclude an exclusively peripheral origin of PD. ${ }^{7172}$

A recent 'threshold hypothesis' argues that PD develops simultaneously in multiple foci of the CNS and PNS that voids the need for pathology spread. ${ }^{78}$ The mechanism underlying this process is the increased susceptibility of specific neurons in GI, olfactory cortex, $\mathrm{SNc}$ and sleep centres to develop LB pathology with the resulting destruction of local networks. Whether and when this network destruction causes symptoms and their severity depends on the intrinsic vulnerability of the neurons and robustness of their circuits, resulting in the overall functional reserve of a particular system. The emphasis of this hypothesis is on the local origin of multiple LB foci and the lesser importance of neuron-to-neuron spread. ${ }^{78}$ The weaknesses are that (1) provides no mechanism to explain selective vulnerability and (2) argues against the spread of pathology as a central mechanism that is consistent with both stereotypic disease progression and experimental data.

\section{Selective neuronal vulnerability}

We propose here a mixed hypothesis that acknowledges a multifocal origin but relies on trans-synaptic spread for the progression to new regions as the disease advances with age. The multifocal origin is supported on the intrinsic vulnerability of dopaminergic neurons, mainly due to their high metabolic demands. ${ }^{59}$ One, the high production of dopamine generates intermediate metabolites that cause oxidative stress. Two, the self-generation of rhythms (pacemaker) that underlies the regular and diffuse distribution of dopamine throughout the brain to maintain basic stimulation, which causes $\mathrm{Ca}+$ overload. Coupled with relatively low ability to buffer cytoplasmic $\mathrm{Ca}+$ (relative low expression of $\mathrm{Ca}+$ binding proteins), $\mathrm{Ca}+$ overload results in mitochondria dysfunction and subsequent oxidative stress. ${ }^{59}$ Over time, oxidative stress and other cellular damage results in $\alpha$-syn misfolding and aggregation into soluble oligomers. These oligomers are highly toxic by mechanisms mostly unknown at this time and 
also act as seeds for the accelerated misfolding of more native $\alpha$-syn. The extracellular release of these $\alpha$-syn oligomers and protofibers activate astrocytes and microglia, generating local inflammation and a robust neuroimmune reaction.

What do we know about the vulnerability of other foci for PD initiation? ENS neurons in the Meissner plexus produce dopamine that maintains the tone in the GI independently of CNS input. This suggests that these dopaminergic neurons in the ENS share the metabolic characteristics of SNc neurons due to dopamine biosynthesis as well as the pacemaking activity. The sleep centre in the brainstem and the autonomic nervous system also have pacemaking activity to regulate critical body functions, highlighting a common physiological feature with dopaminergic neurons and, potentially explaining their vulnerability. Unfortunately, less details are known about other foci for LB initiation in PD (vagus nerve) and in other disorders, like oligodendrocytes in MSA and frontal cortex neurons in LBD. The involvement of different brain regions and cell types indicates that the pathology implicates more than dopamine production. Critical aspects of when, why and where the proteinopathy starts are currently unknown, but ageing and individual risk profiles (genetics, age, exposures) are likely to play a large role in the variable presentation.

Another aspect of the pathology that has been discussed before is the resilience of different neurons to LB pathology. Vagus nerve cells accumulate early LB but do not seem to degenerate; on the other hand, $\mathrm{SNc}$ neurons are highly vulnerable to $\alpha$-syn aggregates, leaving few cells with LB pathology on autopsy. These observations suggest that susceptibility to form LBs and vulnerability are not tied to each other. The molecular mechanisms underlying these differences may involve $\mathrm{Ca}+$ buffering and other cellular mechanisms of proteostasis, but could also be explained by the accumulation of cell-specific $\alpha$-syn strains (see below).

\section{Trans-synaptic spread of protein pathology}

Trans-synaptic spread of the protein pathology mechanistically links the stereotyped progression of PD from $\mathrm{SNc}$ to the frontal cortex through anatomically interconnected pathways. One argument for the prion-like behaviour of $\alpha$-syn comes from the LB pathology of embryonic grafts of dopaminergic cells implanted in the midbrain, suggesting local spread of LB from host SNc neurons with high LB burden. ${ }^{79-81}$ The converging pathology of several synucleinopathies and other proteinopathies strongly supports trans-synaptic spread to both frontal and autonomic centres in both rostral and caudal directions. What is the cellular basis for $\alpha$-syn spreading pathology? Work done in the last decade demonstrates the prion-like features of $\alpha$-syn and other amyloids. ${ }^{82-84}$ For decades, prion diseases enjoyed a unique, defining feature: transmissibility. But at the molecular level, all amyloids share significant structural, biochemical and biological features. ${ }^{65}$ All amyloids aggregate by templated seeded polymerisation, an autocatalytic process mediated by direct contact between seeds containing misfolded protein and natively folded protein. ${ }^{86} 87$ If these proteins follow similar rules in vitro, it should not surprise that they share the same behaviour in complex systems. The mechanism of seeded polymerisation enjoys additional support in the cellular environment from chaperones, membranes and other intracellular substrates, providing a more consistent and predictive basis for the formation and expansion of amyloid aggregation. One predicted property of amyloids is the ability to cross-seed other amyloids based on the presence of conserved 3D domains or conformations. ${ }^{6988}$
Interestingly, $\alpha$-syn has been shown to cross-seed tau, providing additional mechanisms to explain neurodegeneration and concurrent pathologies ${ }^{89} 90$ (figure 1). Hyperphosphorylated, misfolded tau has been proposed as one of the main drivers of neurodegeneration in $\mathrm{AD}$ downstream of the amyloid- $\beta$ peptide and tau pathology is present in a variety of neurodegenerative disorders, including dementias and parkinsonism. These data come together under the provocative idea that tau contributes to PD neurotoxicity downstream of $\alpha$-syn..$^{91}{ }^{92}$ Not everyone agrees with this model, with the main criticism to proteinopathies being the lack of disease-modifying therapies dedicated to the formation/accumulation of amyloids. ${ }^{93}$ The criticism is fair because critical appraisal of hypotheses is a fundamental component of the scientific enterprise. Unfortunately, there are currently no alternative hypotheses that can displace amyloids as central to disease. No other central causes of pathogenesis have emerged so far, only unrelated collections of cellular phenotypes affecting mitochondria, synapses, axons, transcription, calcium metabolism, proteasome, autophagy, apoptosis and so on. The focus on these phenotypes can lead to effective treatments that do not alter the underlying disease pathology, providing limited symptomatic relief for patients similar to L-dopa treatment. But the search for the common underlying mechanisms upstream of all these symptoms should continue in an effort to better understand PD and, eventually, provide the basis for disease-modifying therapies.

But how are large intracellular seeds transferred to neighbouring cells? Although these processes are still under investigation, $\alpha$-syn is released from cells and its proteolytic fragments are highly amyloidogenic. ${ }^{9495}$ Additionally, purified $\alpha$-syn in the medium or from cells overexpressing $\alpha$-syn can penetrate neural stem cells and SY5Y cells, aggregate intracellularly and seed endogenous $\alpha$-syn. ${ }^{96-98}$ Additional mechanisms may involve the release of seeds by membrane breaks in sick cells and the generation of membrane pores, one of the known aberrant behaviours of amyloid oligomers. ${ }^{65}$ These results lend strong support to the prion-like behaviour of $\alpha$-syn..$^{8799} 100$

In support of this prion-like behaviour of $\alpha$-syn, injection of aggregated $\alpha$-syn in the intestinal wall of mice is transported to the vagus nerve, ${ }^{101}$ either actively (the injected seeds) or indirectly, through aggregation of endogenous $\alpha$-syn. Similarly, $\alpha$-syn introduced by virus or rotenone treatment in the GI appears to 'ascend' or spread to CNS neurons. ${ }^{5676} \mathrm{~A}$ puzzling observation is that $\alpha$-syn expressed from viruses still spreads in a rostral direction in $\alpha$-syn KO mice. ${ }^{78} 102$ This actually supports the efficient trans-synaptic spread of $\alpha$-syn without seeded nucleation, although the virus could also spread trans-synaptically, promoting $\alpha$-syn expression in the next postsynaptic neuron. Overall, these observations argue for a mixed model that acknowledges the start of $\alpha$-syn pathology in several foci followed by regional spread through anatomically connected networks.

Furthermore, several studies have reported bona fide transmission of synthetic $\alpha$-syn fibrillar material into wild type mice. ${ }^{103} 104$ These studies show the development of a PD-like disease and spread of $\alpha$-syn pathology to areas far apart from the injection site, supporting the prion-like properties of $\alpha$-syn. Although the use of synthetic fibres addresses the transmissibility of $\alpha$-syn, some may question their disease relevance. A year later, another study published the transmission of MSA-derived brain deposits, but not from patients with PD, into transgenic mice expressing mutant $\alpha$-syn (see below). ${ }^{105}$ Direct transmission of human disease material strongly supports the prion-like properties of $\alpha$-syn, but the transfer into transgenic mice overexpressing 
$\alpha$-syn can also be interpreted as the acceleration of an underlying disease.

\section{One final argument: distinct $\alpha$-syn strains}

The similarities between PD and prion diseases were highlighted recently with the identification of $\alpha$-syn strains with distinct biochemical and biological properties. Three 2013 studies ${ }^{90106107}$ demonstrated for the first time that $\alpha$-syn can form distinctive strains based on the definition of protein strain. ${ }^{108}$ Two of these studies generated synthetic $\alpha$-syn fibres that showed distinct structure, cellular toxicity, seeding properties and propagation in cultured cells. ${ }^{90107}$ The third study demonstrated transmission of $\alpha$-syn pathology from patient brain extracts into cell culture, finding evidence for three different $\alpha$-syn strains in MSA-derived extracts. ${ }^{106}$ Interestingly, this study failed to transmit $\alpha$-syn pathology from extracts of patients with PD, further supporting the heterogenicity of $\alpha$-syn aggregates (or strains). Another study found that two structural forms $\alpha$-syn (ribbons and fibrils) led to different phenotypes when transferred into rats, with the ribbons producing symptoms similar to those of PD and MSA. ${ }^{109}$ Last, a recent work found that an MSA-specific conformation of $\alpha$-syn specifically propagates in oligodendrocytes, the main cell type affected in MSA. ${ }^{110}$ This paper provides evidence for the role of cellular context (cellular milieu) in the propagation and transmission of specific strains, which potentially explains the differences between synucleinopathies. Overall, recent work strongly supports the prion-like behaviour of $\alpha$-syn and, therefore, the likelihood of its trans-synaptic transmission.

\section{Concluding remarks}

Since $\alpha$-syn demonstrates several prion-like properties (experimental transmission, distinct strains), are PD or other synucleinopathies infectious? By extension, are all other proteinopathies (eg, AD) infectious? The clear answer at this time is: no. No epidemiological data support the infectious nature of PD. The iatrogenic transmission of prion diseases was efficiently detected following the mad-cow disease epidemic, leading to bans for blood and organ donations. No such evidence has been uncovered related to $\mathrm{PD}$ or $\mathrm{AD}$, two prevalent disorders among the elderly population. Despite the similarities described above, no amyloid has shown the most distinctive property of prions: resistance to digestion by proteases and denaturing agents. Sensitivity to proteases and other denaturing conditions makes all prionlike amyloids unlikely to resist degradation under conditions that would lead to transmission, like contaminated surgical equipment. $\alpha$-syn transmission in mice was achieved in wild type mice by intracerebral inoculation of highly concentrated seeds. These are ideal conditions for an in vivo seeding experiment, but such conditions do not occur naturally. With the high prevalence of $\mathrm{AD}$ and $\mathrm{PD}$, we have likely been exposed to small amounts of seeds via transfusion, transplants and surgical instruments that should lead to early onset PD, which has not happened. Hence, AD and PD fibres degrade more efficiently than bona fide prions, lack appropriate transmission routes, lack replication sites in peripheral tissues, have long incubation times or the concentration of seeds is extremely small. Therefore, the prionlike behaviour of $\alpha$-syn explains the progressive trans-synaptic spread of pathology, but there is no reason for social alarm. Synucleinopathies are not prions: they only show transmissibility in the lab under highly favourable experimental conditions. While the nature of PD and related disorders continues to be investigated, it would make sense to call for caution when handling patient brains, but there is no need for social alarm or for altering blood donation or surgical protocols.

Acknowledgements We are thankful to the many labs that have contributed to this field and apologise to those whose work we could not cite. The authors are thankful for institutional support for performing the literature research and writing the review.

Contributors LM, WD and PFF conceived the study. LM, WD and PFF performed literature search and contributed to the draft. PFF completed the draft. All authors read and approved the final version.

Funding The authors have not declared a specific grant for this research from any funding agency in the public, commercial or not-for-profit sectors.

Competing interests None declared.

Patient consent for publication Not required.

Provenance and peer review Not commissioned; externally peer reviewed.

ORCID iD

Pedro Fernandez-Funez http://orcid.org/0000-0002-0103-5593

\section{REFERENCES}

1 Kalia LV, Lang AE. Parkinson's disease. The Lancet 2015;386:896-912.

2 Parkinson J. An essay on the shaking palsy. Whittingham \& Rowland London, 1817.

3 Hawkes CH, Del Tredici K, Braak H. Parkinson's disease: a dual-hit hypothesis. Neuropathol App/ Neurobiol 2007:33:599-614.

4 Braak H, Tredici KD, Rüb U, de Vos RAl, Jansen Steur ENH, Braak E. Staging of brain pathology related to sporadic Parkinson's disease. Neurobiol Aging 2003;24:197-211.

5 Shulman JM, De Jager PL, Feany MB. Parkinson's disease: genetics and pathogenesis. Annu Rev Pathol 2011;6:193-222.

6 Singleton $A B$, Hardy JA, Gasser T. The birth of the modern era of parkinson's disease genetics. J Parkinsons Dis 2017;7:S87-S93.

7 Doty RL. Olfactory dysfunction in Parkinson disease. Nat Rev Neurol 2012;8:329-39.

8 Fullard ME, Morley JF, Duda JE. Olfactory Dysfunction as an Early Biomarker in ParkinsonOlfactory dysfunction as an early biomarker in parkinson'DiseaseS disease. Neurosci Bull 2017;33:515-25.

9 Tarakad A, Jankovic J. Anosmia and ageusia in parkinson's disease. Int Rev Neurobiol 2017:133:541-56.

10 Haehner A, Boesveldt S, Berendse HW, Mackay-Sim A, Fleischmann J, Silburn PA, Johnston AN, Mellick GD, Herting B, Reichmann H, Hummel T. Prevalence of smell loss in Parkinson's disease - a multicenter study. Parkinsonism Relat Disord 2009:15:490-4

11 Ross GW, Petrovitch H, Abbott RD, Tanner CM, Popper J, Masaki K, Launer L, White LR. Association of olfactory dysfunction with risk for future Parkinson's disease. Ann Neurol 2008:63:167-73.

12 Jennings D, Siderowf A, Stern M, Seibyl J, Eberly S, Oakes D, Marek K, PARS Investigators. Conversion to Parkinson disease in the pars hyposmic and dopamine Transporter-Deficit prodromal cohort. JAMA Neurol 2017;74:933-40.

13 Adler CH, Connor DJ, Hentz JG, Sabbagh MN, Caviness JN, Shill HA, Noble B, Beach TG. Incidental Lewy body disease: clinical comparison to a control cohort. Mov Disord 2010:25:642-6.

14 Dickson DW, Fujishiro H, DelleDonne A, Menke J, Ahmed Z, Klos KJ, Josephs KA, Frigerio R, Burnett M, Parisi JE, Ahlskog JE. Evidence that incidental Lewy body disease is pre-symptomatic Parkinson's disease. Acta Neuropathol 2008; 115:437-44.

15 Ross GW, Abbott RD, Petrovitch H, Tanner CM, Davis DG, Nelson J, Markesbery WR Hardman J, Masaki K, Launer L, White LR. Association of olfactory dysfunction with incidental Lewy bodies. Mov Disord. 2006;21:2062-7.

16 Doty RL, Deems DA, Stellar S. Olfactory dysfunction in parkinsonism: a general deficit unrelated to neurologic signs, disease stage, or disease duration. Neurology 1988;38:1237-44.

17 Hähner A, Maboshe W, Baptista RB, Storch A, Reichmann H, Hummel T. Selective hyposmia in Parkinson's disease? J Neurol 2013;260:3158-60.

18 Witt M, Bormann K, Gudziol V, Pehlke K, Barth K, Minovi A, Hähner A, Reichmann H, Hummel T. Biopsies of olfactory epithelium in patients with Parkinson's disease. Mov Disord 2009;24:906-14.

19 Duda JE, Shah U, Arnold SE, Lee VM, Trojanowski JQ. The expression of alphabeta-, and gamma-synucleins in olfactory mucosa from patients with and without neurodegenerative diseases. Exp Neurol 1999;160:515-22.

20 Saito Y, Shioya A, Sano T, Sumikura H, Murata M, Murayama S. Lewy body pathology involves the olfactory cells in Parkinson's disease and related disorders. Mov Disord 2016:31:135-8.

21 Altinayar S, Oner S, Can S, Kizilay A, Kamisli S, Sarac K. Olfactory disfunction and its relation olfactory bulb volume in Parkinson's disease. Eur Rev Med Pharmacol Sci 2014;18:3659-64. 
22 Scherfler C, Schocke MF, Seppi K, Esterhammer R, Brenneis C, Jaschke W, Wenning GK, Poewe W. Voxel-wise analysis of diffusion weighted imaging reveals disruption of the olfactory tract in Parkinson's disease. Brain 2006;129:538-42.

23 Oh Y-S, Kim J-S, Hwang E-J, Lyoo CH. Striatal dopamine uptake and olfactory dysfunction in patients with early Parkinson's disease. Parkinsonism Relat Disord 2018:56:47-51.

24 Wen M-C, Xu Z, Lu Z, Chan LL, Tan EK, Tan LCS. Microstructural network alterations of olfactory dysfunction in newly diagnosed Parkinson's disease. Sci Rep 2017;7:12559.

25 Baba T, Takeda A, Kikuchi A, Nishio Y, Hosokai Y, Hirayama K, Hasegawa T, Sugeno N, Suzuki K, Mori E, Takahashi S, Fukuda H, Itoyama Y. Association of olfactory dysfunction and brain. Metabolism in Parkinson's disease. Mov Disord 2011;26:621-8.

26 Chen N-K, Chou Y-H, Sundman M, Hickey P, Kasoff WS, Bernstein A, Trouard TP, Lin T, Rapcsak SZ, Sherman SJ, Weingarten CP. Alteration of diffusion-tensor magnetic resonance imaging measures in brain regions involved in early stages of parkinson's disease. Brain Connect 2018:8:343-9.

27 Takeda A, Saito N, Baba T, Kikuchi A, Sugeno N, Kobayashi M, Hasegawa T, Itoyama Y. Functional imaging studies of hyposmia in Parkinson's disease. J Neuro/ SCi 2010;289:36-9.

28 Arendt T, Bigl V, Arendt A, Tennstedt A. Loss of neurons in the nucleus basalis of Meynert in Alzheimer's disease, paralysis agitans and Korsakoff's disease. Acta Neuropathol 1983;61:101-8.

29 Bohnen NI, Muller MLTM, Kotagal V, Koeppe RA, Kilbourn MA, Albin RL, Frey KA. Olfactory dysfunction, central cholinergic integrity and cognitive impairment in Parkinson's disease. Brain 2010;133:1747-54.

30 Adler CH, Beach TG, Hentz JG, Shill HA, Caviness JN, Driver-Dunckley E, Sabbagh MN, Sue LI, Jacobson SA, Belden CM, Dugger BN. Low clinical diagnostic accuracy of early vs advanced Parkinson disease: clinicopathologic study. Neurology 2014;83:406-12.

31 Ross GW, Abbott RD, Petrovitch H, Tanner CM, White LR. Pre-Motor features of Parkinson's disease: the Honolulu-Asia aging study experience. Parkinsonism Relat Disord 2012;18(Suppl 1):S199-S202.

32 Sommer U, Hummel T, Cormann K, Mueller A, Frasnelli J, Kropp J, Reichmann H. Detection of presymptomatic Parkinson's disease: combining smell tests, transcranial sonography, and SPECT. Mov Disord. 2004;19:1196-202.

33 Rossi M, Escobar AM, Bril A, Millar Vernetti P, De Palo J. I, Cerquetti D, Merello M. Motor features in Parkinson's disease with normal olfactory function. Mov Disord. 2016:31:1414-7.

34 Fernandez HH, Okun MS, Rodriguez RL, Malaty IA, Romrell J, Sun A, Wu SS, Pillarisetty S, Nyathappa A, Eisenschenk S. Quetiapine improves visual hallucinations in Parkinson disease but not through normalization of sleep architecture: results from a double-blind clinical-polysomnography study. Int J Neurosci 2009;119:2196-205

35 Cramer CK, Friedman JH, Amick MM. Olfaction and apathy in Parkinson's disease. Parkinsonism Relat Disord 2010;16:124-6.

36 Hong JY, Sunwoo MK, Ham JH, Lee JJ, Lee PH, Sohn YH. Apathy and Olfactory Dysfunction in Early Parkinson's Disease. JMD 2015;8:21-5.

37 Fullard ME, Tran B, Xie SX, Toledo JB, Scordia C, Linder C, Purri R, Weintraub D, Duda JE, Chahine LM, Morley JF. Olfactory impairment predicts cognitive decline in early Parkinson's disease. Parkinsonism Relat Disord 2016;25:45-51.10.1016/j. parkreldis.2016.02.013

38 Chaudhuri KR, Healy DG, Schapira AHV, National Institute for Clinical Excellence. Non-Motor symptoms of Parkinson's disease: diagnosis and management. Lancet Neurol 2006:5:235-45.

39 Goetze O, Nikodem AB, Wiezcorek J, Banasch M, Przuntek H, Mueller T, Schmidt WE, Woitalla D. Predictors of gastric emptying in Parkinson's disease. Neurogastroenterol Motil 2006;18:369-75.

40 Martinez-Martin P, Rodriguez-Blazquez C, Kurtis MM, Chaudhuri KR, Group N. $V$, NMSS Validation Group. The impact of non-motor symptoms on healthrelated quality of life of patients with Parkinson's disease. Mov Disord 2011;26:399-406.

41 Rodríguez-Violante M, Cervantes-Arriaga A, Villar-Velarde A, Corona T. Prevalence of non-motor dysfunction among Parkinson's disease patients from a tertiary referral center in Mexico City. Clin Neurol Neurosurg 2010;112:883-5.

42 Ashraf W, Pfeiffer RF, Park F, Lof J, Quigley EM. Constipation in Parkinson's disease: objective assessment and response to psyllium. Mov Disord 1997;12:946-51.

43 Abbott RD, Petrovitch H, White LR, Masaki KH, Tanner CM, Curb JD, Grandinetti A Blanchette PL, Popper JS, Ross GW. Frequency of bowel movements and the future risk of Parkinson's disease. Neurology 2001;57:456-62.

44 Savica R, Carlin JM, Grossardt BR, Bower JH, Ahlskog JE, Maraganore DM, Bharucha $A E$, Rocca WA. Medical records documentation of constipation preceding Parkinson disease: a case-control study. Neurology 2009;73:1752-8.

45 Adams-Carr KL, Bestwick JP, Shribman S, Lees A, Schrag A, Noyce AJ. Constipation preceding Parkinson's disease: a systematic review and meta-analysis. J Neurol Neurosurg Psychiatry 2016;87:710-6.

46 Beach TG, Adler CH, Sue LI, Vedders L, Lue L, White III CL, Akiyama H, Caviness JN, Shill HA, Sabbagh MN, Walker DG, Arizona Parkinson's Disease C. Multi-Organ distribution of phosphorylated $\alpha$-synuclein histopathology in subjects with Lewy body disorders. Acta Neuropathol 2010;119:689-702.

47 Gelpi E, Navarro-Otano J, Tolosa E, Gaig C, Compta Y, Rey MJ, Martí MJ, Hernández I, Valldeoriola F, Reñé R, Ribalta T. Multiple organ involvement by alpha-synuclein pathology in Lewy body disorders. Mov Disord 2014;29:1010-8

48 Annerino DM, Arshad S, Taylor GM, Adler CH, Beach TG, Greene JG. Parkinson's disease is not associated with gastrointestinal myenteric ganglion neuron loss. Acta Neuropathol 2012;124:665-80.

49 Lebouvier T, Neunlist M, Bruley des Varannes S, Coron E, Drouard A, N'Guyen J-M, Chaumette T, Tasselli M, Paillusson S, Flamand M, Galmiche J-P, Damier P, Derkinderen P. Colonic biopsies to assess the neuropathology of Parkinson's disease and its relationship with symptoms. PLoS One 2010;5:e12728.

50 Przedborski S. The two-century journey of Parkinson disease research. Nat Rev Neurosci 2017; 18:251-9

51 Ascherio A, Schwarzschild MA. The epidemiology of Parkinson's disease: risk factors and prevention. Lancet Neurol 2016;15:1257-72.

52 Keller MF, Saad M, Bras J, Bettella F, Nicolaou N, Simón-Sánchez J, Mittag F, Büchel F, Sharma M, Gibbs JR, Schulte C, Moskvina V, Durr A, Holmans P, Kilarski LL, Guerreiro R, Hernandez DG, Brice A, Ylikotila P, Stefánsson H, Majamaa K, Morris HR, Williams N, Gasser T, Heutink P, Wood NW, Hardy J, Martinez M, Singleton AB, Nalls MA, International Parkinson's Disease Genomics Consortium (IPDGC). Wellcome Trust Case Control Consortium 2 (WTCCC2). Using genome-wide complex trait analysis to quantify 'missing heritability' in Parkinson's disease. Hum Mol Genet 2012:21:4996-5009.

53 Hallett PJ, McLean JR, Kartunen A, Langston JW, Isacson O. $\alpha$-Synuclein overexpressing transgenic mice show internal organ pathology and autonomic deficits. Neurobiol Dis 2012;47:258-67.

54 Kuo Y-M, Li Z, Jiao Y, Gaborit N, Pani AK, Orrison BM, Bruneau BG, Giasson BI, Smeyne RJ, Gershon MD, Nussbaum RL. Extensive enteric nervous system abnormalities in mice transgenic for artificial chromosomes containing Parkinson disease-associated $\alpha$-synuclein gene mutations precede central nervous system changes. Hum Mol Genet 2010;19:1633-50.

55 Wang L, Magen I, Yuan P-Q, Subramaniam SR, Richter F, Chesselet M-F, Taché $Y$. Mice overexpressing wild-type human alpha-synuclein display alterations in colonic myenteric ganglia and defecation. Neurogastroenterol Motil 2012;24:e425-36.

56 Pan-Montojo F, Schwarz M, Winkler C, Arnhold M, O'Sullivan GA, Pal A, Said J, Marsico G, Verbavatz J-M, Rodrigo-Angulo M, Gille G, Funk RHW, Reichmann H. Environmental toxins trigger PD-like progression via increased alpha-synuclein release from enteric neurons in mice. Sci Rep 2012;2:898.

57 Svensson E, Horváth-Puhó E, Thomsen RW, Djurhuus JC, Pedersen L, Borghammer $\mathrm{P}$, Sørensen HT. Vagotomy and subsequent risk of Parkinson's disease. Ann Neurol 2015:78:522-9.

58 Zhang P-L, Chen Y, Zhang C-H, Wang Y-X, Fernandez-Funez P. Genetics of Parkinson's disease and related disorders. J Med Genet 2018;55:73-80.

59 Surmeier DJ, Obeso JA, Halliday GM. Selective neuronal vulnerability in Parkinson disease. Nat Rev Neurosci 2017;18:101-13.

60 Alessi DR, Sammler E. Lrrk2 kinase in Parkinson's disease. Science 2018:360:36-7.

61 Titova N, Padmakumar C, Lewis SJG, Chaudhuri KR. Parkinson's: a syndrome rather than a disease? J Neural Transm 2017:124:907-14.

62 Jellinger KA. Lewy body-related ?-synucleinopathy in the aged human brain. J Neural Transm 2004:111:1219-35.

63 Dickson DW. Neuropathology of Parkinson disease. Parkinsonism Relat Disord 2018:46(Suppl 1):S30-\$33.

64 Braak H, Ghebremedhin E, Rüb U, Bratzke H, Del Tredici K. Stages in the development of Parkinson's disease-related pathology. Cell Tissue Res 2004:318:121-34.

65 Glabe CG, Kayed R. Common structure and toxic function of amyloid oligomers implies a common mechanism of pathogenesis. Neurology 2006;66(Issue 1 , Supplement 1):S74-S78.

66 Benilova I, Karran E, De Strooper B. The toxic A oligomer and Alzheimer's disease: an emperor in need of clothes. Nat Neurosci 2012;15:349-57.

67 Tokuda T, Qureshi MM, Ardah MT, Varghese S, Shehab SAS, Kasai T, Ishigam N, Tamaoka A, Nakagawa M, El-Agnaf OMA. Detection of elevated levels of $\alpha$-synuclein oligomers in CSF from patients with Parkinson disease. Neurology 2010:75:1766-70.

68 El-Agnaf OMA, Salem SA, Paleologou KE, Curran MD, Gibson MJ, Court JA, Schlossmacher MG, Allsop D. Detection of oligomeric forms of $\alpha$-synuclein protein in human plasma as a potential biomarker for Parkinson's disease. FASEB $\mathrm{J}$ 2006:20:419-25.

69 Kayed R, Head E, Thompson JL, McIntire TM, Milton SC, Cotman CW, Glabe CG. Common structure of soluble amyloid oligomers implies common mechanism of pathogenesis. Science 2003;300:486-9.

70 Olanow CW, Perl DP, DeMartino GN, McNaught KSP. Lewy-Body formation is an aggresome-related process: a hypothesis. Lancet Neurol 2004;3:496-503.

71 Kalaitzakis ME, Graeber MB, Gentleman SM, Pearce RKB. The dorsal motor nucleus of the vagus is not an obligatory trigger site of Parkinson's disease: a critical analysis of alpha-synuclein staging. Neuropathol App/ Neurobiol 2008;34:284-95. 
72 Attems J, Jellinger KA. The dorsal motor nucleus of the vagus is not an obligatory trigger site of Parkinson's disease. Neuropathol App/ Neurobiol 2008;34:466-7.

73 Parkkinen L, Pirttilä T, Alafuzoff I. Applicability of current staging/categorization of $\alpha$-synuclein pathology and their clinical relevance. Acta Neuropathol 2008; 115:399-407

74 Zaccai J, Brayne C, McKeith I, Matthews F, Ince PG, Mrc Cognitive Function ANS, On behalf of the MRC Cognitive Function, Ageing Neuropathology Study. Patterns and stages of -synucleinopathy: Relevance in a population-based cohort. Neurology 2008;70:1042-8

75 Wakabayashi K, Toyoshima Y, Awamori K, Anezaki T, Yoshimoto M, Tsuji S, Takahashi $\mathrm{H}$. Restricted occurrence of Lewy bodies in the dorsal vagal nucleus in a patient with late-onset parkinsonism. J Neuro/ Sci 1999;165:188-91.

76 Ulusoy A, Rusconi R, Pérez-Revuelta BI, Musgrove RE, Helwig M, Winzen-Reichert $B$, Monte DAD. Caudo-rostral brain spreading of $\alpha$-synuclein through vagal connections. EMBO Mol Med 2013:5:1119-27.

77 Tysnes O-B, Kenborg L, Herlofson K, Steding-Jessen M, Horn A, Olsen JH, Reichmann H. Does vagotomy reduce the risk of Parkinson's disease? Ann Neurol 2015;78:1011-2.

78 Engelender S, Isacson 0. The threshold theory for parkinson's disease. Trends Neurosci 2017;40:4-14

79 Li W, Englund E, Widner H, Mattsson B, van Westen D, Lätt J, Rehncrona S, Brundin

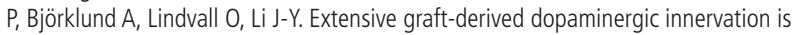
maintained 24 years after transplantation in the degenerating parkinsonian brain. Proc Natl Acad Sci U S A 2016:113:6544-9.

80 Li J-Y, Englund E, Holton JL, Soulet D, Hagell P, Lees AJ, Lashley T, Quinn NP, Rehncrona S, Björklund A, Widner H, Revesz T, Lindvall O, Brundin P. Lewy bodies in grafted neurons in subjects with Parkinson's disease suggest host-to-graft disease propagation. Nat Med 2008;14:501-3.

81 Kordower JH, Chu Y, Hauser RA, Freeman TB, Olanow CW. Lewy body-like pathology in long-term embryonic nigral transplants in Parkinson's disease. Nat Med 2008;14:504-6.

82 Stopschinski BE, Diamond MI. The prion model for progression and diversity of neurodegenerative diseases. Lancet Neurol 2017;16:323-32.

83 Jucker M, Walker LC. Propagation and spread of pathogenic protein assemblies in neurodegenerative diseases. Nat Neurosci 2018;21:1341-9.

84 Guo JL, Lee VMY. Cell-To-Cell transmission of pathogenic proteins in neurodegenerative diseases. Nat Med 2014;20:130-8

85 ladanza MG, Jackson MP, Hewitt EW, Ranson NA, Radford SE. A new era for understanding amyloid structures and disease. Nat Rev Mol Cell Biol 2018;19:755-73.

86 Scheckel C, Aguzzi A. Prions, prionoids and protein misfolding disorders. Nat Rev Genet 2018;19:405-18.

87 Aguzzi A, Rajendran L. The transcellular spread of cytosolic amyloids, prions, and prionoids. Neuron 2009;64:783-90.

88 Kayed R, Glabe CG. Conformation-dependent anti-amyloid oligomer antibodies. Methods Enzymol 2006:413:326-44.

89 Castillo-Carranza DL, Guerrero-Muñoz MJ, Sengupta U, Gerson JE, Kayed R. Alphasynuclein oligomers induce a unique toxic tau strainalpha-Synuclein Oligomers Induce a Unique Toxic Tau Strain. Biol Psychiatry 2018;84:499-508.

90 Guo JL, Covell DJ, Daniels JP, Iba M, Stieber A, Zhang B, Riddle DM, Kwong LK, Xu Y, Trojanowski JQ, Lee VMY. Distinct $\alpha$-synuclein strains differentially promote tau inclusions in neurons. Cell 2013;154:103-17.

91 Singh B, Covelo A, Martell-Martínez H, Nanclares C, Sherman MA, Okematti E, Meints J, Teravskis PJ, Gallardo C, Savonenko AV, Benneyworth MA, Lesné SE, Liao D, Araque A, Lee MK. Tau is required for progressive synaptic and memory deficits in a transgenic mouse model of $\alpha$-synucleinopathy. Acta Neuropathol 2019;21.

92 Gerson JE, Farmer KM, Henson N, Castillo-Carranza DL, Carretero Murillo M, Sengupta U, Barrett A, Kayed R. Tau oligomers mediate $\alpha$-synuclein toxicity and can be targeted by immunotherapy. Mol Neurodegener 2018;13:13.
93 Espay AJ, Vizcarra JA, Marsili L, Lang AE, Simon DK, Merola A, Josephs KA, Fasano A, Morgante F, Savica R, Greenamyre JT, Cambi F, Yamasaki TR, Tanner CM, Gan-Or Z, Litvan I, Mata IF, Zabetian CP, Brundin P, Fernandez HH, Standaert DG, Kauffman MA, Schwarzschild MA, Sardi SP, Sherer T, Perry G, Leverenz JB. Revisiting protein aggregation as pathogenic in sporadic Parkinson and Alzheimer diseases. Neurology 2019:92:329-37.

94 Sung JY, Park SM, Lee C-H, Um JW, Lee HJ, Kim J, Oh YJ, Lee S-T, Paik SR, Chung KC. Proteolytic cleavage of extracellular secreted \{alpha\}-synuclein via matrix metalloproteinases. J Biol Chem 2005;280:25216-24.

95 Lee H-J, Patel S, Lee SJ. Intravesicular Localization and Exocytosis of -Synuclein and its Aggregates. J Neurosci 2005;25:6016-24.

96 Desplats P, Lee H-J, Bae E-J, Patrick C, Rockenstein E, Crews L, Spencer B, Masliah $E$, Lee $S$-J. Inclusion formation and neuronal cell death through neuron-to-neuron transmission of -synuclein. Proc Natl Acad Sci U S A 2009;106:13010-5.

97 Lee H-J, Suk J-E, Bae E-J, Lee J-H, Paik SR, Lee S-J. Assembly-dependent endocytosis and clearance of extracellular a-synuclein. Int J Biochem Cell Biol 2008:40:1835-49.

98 Danzer KM, Krebs SK, Wolff M, Birk G, Hengerer B. Seeding induced by $\alpha$-synuclein oligomers provides evidence for spreading of $\alpha$-synuclein pathology. J Neurochem 2009;111:192-203.

99 Brundin P, Melki R, Kopito R. Prion-Like transmission of protein aggregates in neurodegenerative diseases. Nat Rev Mol Cell Biol 2010;11:301-7.

100 Lee S-J, Desplats P, Sigurdson C, Tsigelny I, Masliah E. Cell-To-Cell transmission of non-prion protein aggregates. Nat Rev Neurol 2010;6:702-6.

101 Holmqvist S, Chutna O, Bousset L, Aldrin-Kirk P, Li W, Björklund T, Wang Z-Y, Roybon L, Melki R, Li J-Y. Direct evidence of Parkinson pathology spread from the gastrointestinal tract to the brain in rats. Acta Neuropathol 2014;128:805-20.

102 Helwig M, Klinkenberg M, Rusconi R, Musgrove RE, Majbour NK, El-Agnaf OMA Ulusoy A, Di Monte DA. Brain propagation of transduced $\alpha$-synuclein involves non-fibrillar protein species and is enhanced in $\alpha$-synuclein null mice. Brain 2016;139:856-70.

103 Luk KC, Kehm V, Carroll J, Zhang B, O'Brien P, Trojanowski JQ, Lee VM-Y. Pathological $\alpha$-synuclein transmission initiates Parkinson-like neurodegeneration in nontransgenic mice. Science 2012;338:949-53.

104 Sacino AN, Brooks M, McGarvey NH, McKinney AB, Thomas MA, Levites Y, Ran Y, Golde TE, Giasson BI. Induction of CNS $\alpha$-synuclein pathology by fibrillar and nonamyloidogenic recombinant $\alpha$-synuclein. Acta Neuropathol Commun 2013;1.

105 Prusiner SB, Woerman AL, Mordes DA, Watts JC, Rampersaud R, Berry DB, Patel S, Oehler A, Lowe JK, Kravitz SN, Geschwind DH, Glidden DV, Halliday GM, Middleton LT, Gentleman SM, Grinberg LT, Giles K. Evidence for $\alpha$-synuclein prions causing multiple system atrophy in humans with parkinsonism. Proc Natl Acad Sci U SA 2015;112:E5308-17.

106 Woerman AL, Stöhr J, Aoyagi A, Rampersaud R, Krejciova Z, Watts JC, Ohyama T, Patel S, Widjaja K, Oehler A, Sanders DW, Diamond MI, Seeley WW, Middleton LT, Gentleman SM, Mordes DA, Südhof TC, Giles K, Prusiner SB. Propagation of prions causing synucleinopathies in cultured cells. Proc Natl Acad Sci U S A 2015;112:E4949-58.

107 Bousset L, Pieri L, Ruiz-Arlandis G, Gath J, Jensen PH, Habenstein B, Madiona K, Olieric V, Böckmann A, Meier BH, Melki R. Structural and functional characterization of two alpha-synuclein strains. Nat Commun 2013;4:2575.

108 Walker LC. Proteopathic strains and the heterogeneity of neurodegenerative diseases. Annu Rev Genet 2016;50:329-46.

109 Peelaerts W, Bousset L, Van der Perren A, Moskalyuk A, Pulizzi R, Giugliano M, Van den Haute C, Melki R, Baekelandt V. $\alpha$-Synuclein strains cause distinct synucleinopathies after local and systemic administration. Nature 2015;522:340-4

110 Peng C, Gathagan RJ, Covell DJ, Medellin C, Stieber A, Robinson JL, Zhang B, Pitkin RM, Olufemi MF, Luk KC, Trojanowski JQ, Lee VM-Y. Cellular milieu imparts distinct pathological $\alpha$-synuclein strains in $\alpha$-synucleinopathies. Nature 2018;557:558-63. 